\title{
Improved method of superovulation in monovulatory brushtail possums (Trichosurus vulpecula) using pregnant mares' serum gonadotrophin-luteinizing hormone
}

\author{
A. M. Glazier and F. C. Molinia \\ Cooperative Research Centre for Conservation and Management of Marsupials at Manaaki \\ Whenua-Landcare Research, PO Box 69, Lincoln, Canterbury, New Zealand
}

\begin{abstract}
A new superovulation regimen for the monovulatory brushtail possum (Trichosurus vulpecula) has been devised. It reduces the number of hormone treatments required and elicits a better rate of ovulation than the established pregnant mares' serum gonadotrophin (PMSG)-GnRH method. Ovarian stimulation was achieved by a single intramuscular injection of 15 iu PMSG. This treatment resulted in the recruitment and development of a large number (9-12) of Graafian follicles on the ovaries. Induction of ovulation was achieved by a single intramuscular injection of 2-10 mg pig LH or multiple intramuscular injections of $\mathrm{GnRH},(4 \times 50 \mu \mathrm{g}, 90 \mathrm{~min}$ apart) given $72 \mathrm{~h}$ after PMSG treatment. Superovulation occurred in all animals $(n=48)$ examined $48 \mathrm{~h}$ after treatment irrespective of dose of LH or type of ovulatory stimulus used. The highest ovulatory success $(83 \%)$, the maximum number of ovulation sites $(9.5 \pm 2.8)$ and the highest number of oocytes recovered $(9.0 \pm 2.5)$ were achieved after treatment with PMSG and $4 \mathrm{mg} \mathrm{LH}$. These results were significantly greater than the ovulatory success $(43 \%)$, numbers of ovulation sites (3.9 \pm 1.1$)$ and number of oocytes recovered $(2.1 \pm 0.9)$ after PMSG-GnRH treatment $(P<0.05)$. This simpler and more effective superovulation protocol should assist with more effective manipulation of possum reproduction in captivity.
\end{abstract}

\section{Introduction}

The introduced brushtail possum (Trichosurus vulpecula) poses a serious threat to native New Zealand wildlife and is also a carrier of bovine tuberculosis which it can spread to farmed livestock (Livingstone, 1991). Great emphasis has been placed on finding new methods of controlling possums as conventional methods, such as poisoning, are costly and unsustainable in the long term (Hickling, 1994). One new method is the biological control of fertility (immunocontraception) (Jolly, 1993). Testing for immunocontraceptive effects on gametes would be facilitated by the availability of a suitable in vitro fertilization (IVF) system. In vitro fertilization has been achieved in an American marsupial (Taggart et al., 1993) but not in an Australian species (Rodger, 1994). Since possums are monovular (Tyndale-Biscoe and Renfree, 1987), an efficient and simple superovulation regimen is required to produce large numbers of eggs for screening of candidate contraceptive antigens (Rodger, 1997). Such a regimen would also improve the manipulation of marsupial reproduction in captivity for the study of early marsupial cellular and molecular development, and it has potential in the application of new reproductive technologies for the conservation of endangered species.

Superovulation in possums was first achieved by Harding (1969) using multiple injections of pregnant mares' serum

Received 19 May 1997. gonadotrophin (PMSG) alone or in combination with hCG, a method that led to the recovery of superovulated oocytes in only three animals and the entrapment of oocytes in luteinizing follicles. This methodology was developed further by Rodger and Mate (1988) who recovered multiple mature oocytes (8-24) by treating Australian captured animals with 10 iu PMSG followed 3 days later by multiple doses of synthetic GnRH. In the hands of the present authors, this method worked poorly and, after treatment, a number of seemingly mature follicles remained on the ovaries of stimulated animals. In tammar wallabies (Macropus engenii), pig LH has been used in place of $\mathrm{GnRH}$ as the ovulatory stimulus, resulting in the recovery of a significantly greater number of eggs (Molinia et al., in press).

The present study was designed to investigate whether a PMSG-LH superovulation regimen offered improved efficacy and ease of use in possums compared with the established method of PMSG-GnRH (Rodger and Mate, 1988).

\section{Materials and Methods}

All experiments were conducted in October and November, when possums in the Canterbury region of New Zealand are entering seasonal anoestrus and ovarian response to PMSG is near maximal (A. M. Glazier, unpublished). 


\section{Animals}

Female brushtail possums (Trichosurus vulpecula) were trapped locally and transported to the Landcare Research Animal Facility at Lincoln. On arrival, animals were weighed, their general condition was assessed, and they were housed in individual cages. They had access to water ad libitum and were fed a diet of fresh fruit, vegetables and cereal pellets. All animals used weighed $2.0-2.5 \mathrm{~kg}$ and had a well-developed pouch, indicating sexual maturity.

All experiments were performed in accordance with the 1987 Animals Protection (Codes of Ethical Conduct) Regulations of New Zealand and approved by the Animal Ethics Committee, Landcare Research.

\section{Superovulation}

In all experiments, PMSG was made from a single batch of hormone, and both $\mathrm{GnRH}$ and $\mathrm{LH}$ were from the same batches to reduce variability of response due to batch effects.

\section{GnRH}

Within $4 \mathrm{~h}$ of arrival at the Animal Facility, female possums $(n=6)$ were given a single i.m. injection of 15 iu PMSG (Folligon; Intervet, Oss) dissolved in sterile water. After $72 \mathrm{~h}$, the possums were given $4 \times 50 \mu \mathrm{g}$ i.m. injections of $\mathrm{GnRH}$ (Fertagyl; Intervet, Oss) at intervals of $90 \mathrm{~min}$.

\section{LH}

Groups of female possums ( $n=6$ per treatment group) were primed with PMSG as above and then treated $72 \mathrm{~h}$ later with a single i.m. injection of $2.0,2.5,3.0,4.0,5.0,7.5$, or $10.0 \mathrm{mg}$ LH (Lutropin-V, Vetrepharm, London, Ontario).

\section{Controls}

One control group of possums $(n=6)$ was treated with PMSG as above and then given a $0.5 \mathrm{ml}$ saline injection instead of LH, and a further group $(n=6)$ was given saline only in place of PMSG and LH, respectively.

\section{Examination of reproductive tracts}

Possums were anaesthetized by $\mathrm{CO}_{2}: \mathrm{O}_{2}(3: 1)$ mixture, and then killed by a single intracardiac injection of $1.5 \mathrm{ml}$ sodium pentabarbitol (300 $\mathrm{mg} \mathrm{ml}^{-1}$ ) $48 \mathrm{~h}$ after the first $\mathrm{GnRH}$ injection or LH injection and their reproductive tracts were removed whole. The time of euthanasia was determined from preliminary experiments indicating that no further ovulations occur $48 \mathrm{~h}$ after LH. The uteri were dissected away from the vaginal complex and the ovaries were cut from the distal end of the oviduct. The oviducts and uteri were flushed using a 25 gauge needle and a syringe containing PBS and 10 iu heparin $\mathrm{ml}^{-1}$ (Sigma, St Louis, MO) filter sterilized through a $0.22 \mu \mathrm{m}$ membrane (Millipore, Bedford, MA). Flushed oocytes were collected and fixed for $30 \mathrm{~min}$ in $3 \%$ formalin solution, washed through two changes of PBS, and then placed into a resting drop of PBS under oil. Oocytes were examined and then stored for further investigation.

The ovaries of all animals were examined using a low power stereomicroscope (Leica MZ 12). Ovulation sites, the number of large ( $>2 \mathrm{~mm}$ diameter), unruptured follicles and the number of small $(<2 \mathrm{~mm})$ follicles that remained were counted. The diameters of these follicles were measured using an eyepiece graticule calibrated against a stage scale, and only follicles that had evidence of good vascularization and had clear follicular fluid were included in the counts. The number of oocytes flushed from the oviduct-uteri complex was compared with the number of ovulation sites on the ovaries. The ovulatory success of possums was expressed as a percentage and calculated as $N /(N 1+N) \times 100$, where $N=$ number of ovulations, $N 1=$ number of remaining large $(>2 \mathrm{~mm}$ diameter) follicles, and $N 1+N=$ the total number of large follicles recruited by treatment with PMSG.

\section{Statistical analysis}

Values are presented as means and mean percentages \pm SEM. Data from the study on the dose response of animals to $\mathrm{LH}$ were log transformed to achieve homogeneity of variance and were analysed by a one-way ANOVA with a post-hoc test on pairs of means using Tukey's highest significant difference (HSD) procedure (Wilkinson, 1989). The bodyweights of possums in both $\mathrm{LH}$ and $\mathrm{GnRH}$ treatment groups were analysed by one-way ANOVA and then an analysis of covariance was conducted to verify that bodyweight did not influence ovulatory success. Percentages were compared using chi-squared analysis of contingency tables and means \pm SEM were compared using Student's $t$ test.

\section{Results}

Ovarian response of possums to pregnant mares' serum gonadotrophin

Possums did not respond to priming with PMSG in a predictable manner. Although all animals responded to PMSG treatment, the range of response, as demonstrated by the mean number of follicles $(N+N 1)$, was between 6 and 12 (Table 1 ). The total number of follicles $(N+N 1)$ varied significantly among doses of LH (ANOVA: $F=3.3$; $P<0.05$ ) with maximum numbers at doses of $2 \mathrm{mg}$ and $4-5 \mathrm{mg} \mathrm{LH}$ (Fig. I). The mean number of follicles promoted when GnRH was administered was $8.7 \pm 1.4(n=6)$. The mean number of small $(<2 \mathrm{~mm})$ follicles that remained on the ovaries of animals showed no significant variation across all treatments (ANOVA: $F=0.9: P<0.05)$. Animals injected with saline only exhibited a range of small follicles, all of which were $<2 \mathrm{~mm}$ in diameter or the ovaries had no follicles.

The bodyweights of all animals used across $\mathrm{LH}$ and GnRH treatments exhibited no significant difference (ANOVA: $F=0.88 ; P<0.05$ ).

\section{Effects of $G n R H$ on ovulation}

The ovulatory success with $\mathrm{GnRH}$ as the ovulatory stimulus was $43 \%$, with a mean number of ovulation sites of $3.9 \pm 1.1$. 
Table 1. Effect of GnRH and different doses of LH on the number of ovulation sites, oocytes collected, and follicles $>2 \mathrm{~mm}$ remaining on the ovaries of brushtail possums (Trichosurus vulpecula) after induction of ovulation (means \pm SEM)

\begin{tabular}{ccccc}
\hline $\begin{array}{l}\text { Ovulatory } \\
\text { stimulus }\end{array}$ & $\begin{array}{c}\text { Number of } \\
\text { ovulation } \\
\text { sites }\end{array}$ & $\begin{array}{c}\text { Number of oocytes } \\
\text { recovered per animal } \\
\text { (\% recovery) }\end{array}$ & $\begin{array}{c}\text { Number of } \\
\text { follicles }>2 \mathrm{~mm} \\
\text { remaining on } \\
\text { ovaries }\end{array}$ & $\begin{array}{c}\text { Number of } \\
\text { follicles }<2 \mathrm{~mm} \\
\text { remaining on } \\
\text { ovaries }\end{array}$ \\
\hline $0 \mathrm{mg} \mathrm{LH}$ & 0 & 0 & $11.3 \pm 0.8$ & $8.6 \pm 2.1$ \\
$2.0 \mathrm{mg} \mathrm{LH}$ & $4.3 \pm 1.2$ & $4.3 \pm 1.2(100)$ & $7.0 \pm 1.3$ & $8.7 \pm 1.1$ \\
$2.5 \mathrm{mg} \mathrm{LH}$ & $2.3 \pm 0.6$ & $2.3 \pm 0.6(100)$ & $4.3 \pm 0.4$ & $8.8 \pm 2.3$ \\
$3.0 \mathrm{mg} \mathrm{LH}$ & $4.3 \pm 0.4$ & $4.3 \pm 0.7(98)$ & $2.5 \pm 0.6$ & $12.8 \pm 3.0$ \\
$4.0 \mathrm{mg} \mathrm{LH}$ & $9.5 \pm 2.8^{\mathrm{a}}$ & $9.0 \pm 2.5^{\mathrm{a}}(95)$ & $2.8 \pm 0.4$ & $11.3 \pm 1.2$ \\
$5.0 \mathrm{mg} \mathrm{LH}$ & $5.7 \pm 1.6$ & $5.5 \pm 1.8(96)$ & $5.6 \pm 1.4$ & $12.3 \pm 2.3$ \\
$7.5 \mathrm{mg} \mathrm{LH}$ & $5.9 \pm 1.8$ & $5.6 \pm 1.8(95)$ & $3.3 \pm 1.1$ & $13.8 \pm 2.4$ \\
$10.0 \mathrm{mg} \mathrm{LH}$ & $3.0 \pm 0.3$ & $2.5 \pm 0.4(83)$ & $3.5 \pm 0.3$ & $8.8 \pm 2.3$ \\
$4 \times 50 \mu \mathrm{G} \mathrm{GnRH}$ & $3.9 \pm 1.1$ & $2.1 \pm 0.9(54)$ & $4.8 \pm 1.4$ & $7.8 \pm 1.4$ \\
\hline
\end{tabular}

${ }^{\text {aS }}$ ignificantly greater $(P<0.05)$ than $\mathrm{GnRH}$.

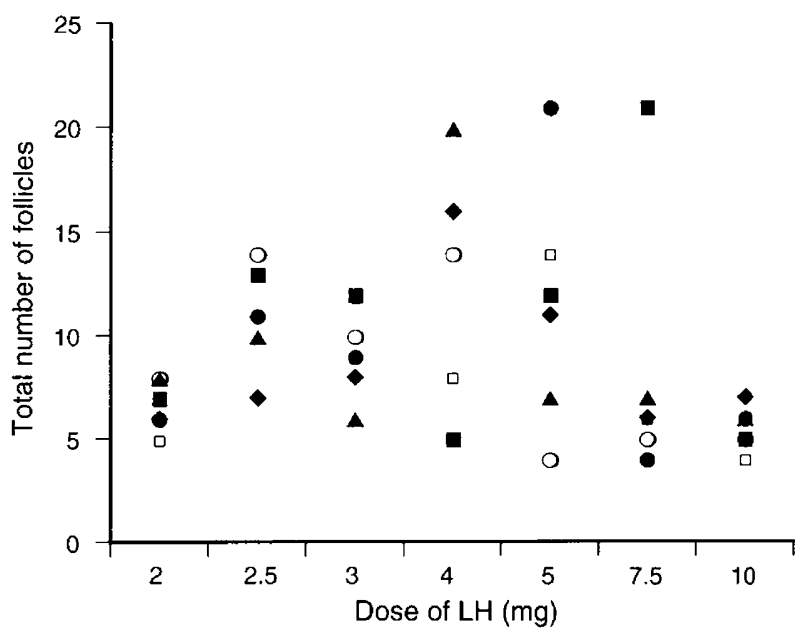

Fig. 1. A scatter plot of the response of individual brushtail possums (Trichosurus vulpecula) to treatment with 15 iu pregnant mares' serum gonadotrophin. Each point represents the total number of follicles $>2 \mathrm{~mm}$ promoted per animal. With each treatment, six animals were stimulated. $\mathbf{\square}, \boldsymbol{\bullet}, \boldsymbol{\Lambda}, \bullet, \square$ and $\bigcirc$ correspond to animals $1,2,3,4$, 5 and 6 at each treatment.

The recovery rate of oocytes was $54 \%$, with only $2.1 \pm 0.9$ oocytes recovered per animal and $4.8 \pm 1.4$ follicles $>2 \mathrm{~mm}$ remaining on the ovaries.

\section{Effects of $L H$ dose on ovulation}

When increasing doses of $\mathrm{LH}$ from 2 to $10 \mathrm{mg}$ were administered to possums, the mean number of ovulations per animal increased to a maximum at $4 \mathrm{mg} \mathrm{LH}$ and then decreased when higher doses were administered (Table I). At $4 \mathrm{mg} \mathrm{LH}$, the ovulatory success was $83 \%$ and the mean number of ovulation sites was $9.5 \pm 2.8$. The number of recovered oocytes closely matched the number of ovulation points on the ovaries of possums at all doses of LH (Table 1). The mean number of follicles $>2 \mathrm{~mm}$ remaining on the ovaries was inversely related to the ovulatory success, with the lowest number occurring at a dose of $3 \mathrm{mg}$ LH $(2.5 \pm 0.6)$ (Table 1). The recovery of oocytes ranged from 83 to $100 \%$ with different doses of LH. The maximum number of oocytes recovered $(9.0 \pm 2.5)$ was achieved at a dose of $4 \mathrm{mg}$ LH.

The ovulatory success did not vary significantly with dose of LH (ANOVA: $F=1.1 ; P>0.05$ ) and there was no significant effect of bodyweight on the ovulatory success for all doses of $\mathrm{LH}$ used and $\mathrm{GnRH}(F=6.6 ; P>0.05)$.

Control animals given PMSG but injected with saline rather than LH failed to ovulate although the ovarian response to PMSG was similar to that seen with LH-treated animals (see Table 1).

\section{Comparison of $L H$ and $G n R H$}

The ovulatory success and the number of oocytes recovered per animal using a $4 \mathrm{mg} \mathrm{LH}$ dose were each significantly greater $(P<0.05)$ than those of possums treated with $\mathrm{GnRH}$ (Table 1 ). The recovery rate of oocytes at all doses of $\mathrm{LH}$ was also significantly greater $(P<0.05)$ than those obtained using $\mathrm{GnRH}$ as the ovulatory stimulus (Table 1 ). There were no significant differences between the ovulatory successes at all other LH doses compared with GnRH treatment (Tukey HSD; $P<0.05$ ).

\section{Examination of oocytes}

All of the oocytes flushed from the oviduct-uterus complexes from both $\mathrm{LH}$ and $\mathrm{GnRH}$ treatments were found to have acquired thick mucoid layers, similar to those seen in normal monovular cycles, indicating that the hormonal manipulation had not affected tubal transport of the oocytes. In addition, all oocytes were exhibiting degeneration, with fragmentation of the chromatin into clumps, and the presence of polar bodies 
was either obscured or they too had degenerated and were no longer visible. Attempts to stain these oocytes fluorescently yielded no further data.

\section{Discussion}

Rodger and Mate (1988) reported that treatment with 10 iu PMSG and three doses of $50 \mu \mathrm{g}$ GnRH optimally superovulated brushtail possums in Australia. In preliminary studies, priming New Zealand possums as described by Rodger and Mate (1988) resulted in the recruitment and development of few follicles (2-3 at $10 \mathrm{iu}$ ) and ovulation of only one or two oocytes (A. M. Glazier, unpublished). In the present study, it was necessary to use higher doses of PMSG and GnRH (15 iu PMSG, $4 \times 50 \mu \mathrm{g} \mathrm{GnRH}$ ) than those previously reported to superovulate possums optimally (Rodger and Mate, 1988) to compensate for the generally higher bodyweights of New Zealand possums (Cowan, 1990).

The use of 15 iu PMSG and $4 \mathrm{mg} \mathrm{LH}$ in the present study resulted in a significantly greater ovulatory success, greater recovery of oocytes and fewer remaining large $(>2 \mathrm{~mm})$, unovulated follicles on the ovaries than with 15 iu PMSG and $\mathrm{GnRH}$ treatment. Since the total number of large follicles per possum in response to PMSG-GnRH or PMSG-LH treatment was similar, it follows that treatment with LH stimulated ovulation of a larger cohort of follicles and resulted in the recovery of a larger number of ovulated oocytes. Although superovulation with $\mathrm{LH}$ yielded greater numbers of oocytes than did the GnRH treatment, some large follicles that appeared capable of providing further oocytes remained on the ovaries. With GnRH-treated animals, ovulation sites were observed on the ovaries of all animals but the recovery rate of ovulated oocytes was much lower than that achieved with $4 \mathrm{mg} \mathrm{LH}$. This may be due to retention of the oocyte in the ruptured follicle as a result of premature luteinization (Harding, 1969).

Follicles need to achieve a critical size of approximately $2 \mathrm{~mm}$ diameter to undergo ovulation in response to either $\mathrm{LH}$ or GnRH (Molinia et al., in press). Increasing the dose of $\mathrm{LH}$ might be expected to increase the number of large follicles that ovulate. However, in the present study, the mean number of ovulations per animal and the ovulatory success reached a maximum at a dose of $4 \mathrm{mg} \mathrm{LH}$ and decreased at higher doses. This finding suggests that factors other than size may prevent seemingly mature follicles from rupturing. One explanation is that the largest (and hence the most mature) follicles rupture first in response to LH. These large follicles, once ovulated, start the process of luteinization and release the subordinate follicles from growth suppression, allowing them to resume development (Kaneko et al., 1995). These follicles may not have been sufficiently mature at the time of $\mathrm{LH}$ treatment to trigger an ovulation response, and hence remain on the ovaries.

Little is known about the mechanisms controlling follicular development in possums. With the exception of data on tammar wallabies (Hinds et al., 1996), there is little information about the hormonal control of folliculogenesis in specific marsupial species. The promoted follicles are thought to require receptors for $\mathrm{LH}$ for ovulation to occur. In tammar wallabies, LH receptors first appear in the final stages of folliculogenesis but are absent from the corpus luteum (Stewart and Tyndale-
Biscoe, 1982). When during the superovulation treatment of possums receptors for $\mathrm{LH}$ appear is unknown. This information is important for accurate timing of LH injection to be determined for successful AI procedures (Molinia et al., 1998) and the recovery of in vivo matured oocytes.

Although this improved protocol produces a large number of oocytes by hormonal stimulation, it is vital that these oocytes are able to be fertilized and undergo normal zygotic development if they are to be of use in assisted breeding programmes involving artificial insemination (Molinia et al., in press) or in in vitro biocontrol assays (Rodger, 1997). In eutherian species, superovulation produces cohorts of oocytes that are meiotically immature and require further culture either in intact follicles or after retrieval from the follicle (Spears $e t a l$., 1994). Structural and physiological assessments of superovulated oocytes from possums are currently underway. It remains to be seen whether superovulated animals will mate successfully in captivity, and are able to support pregnancy to term and produce live young.

The primary aim of the present study has been achieved by providing a simplified PMSG-LH protocol that produces a more reliable and consistent rate of ovulation and yields a large number of seemingly mature oocytes that can be used for further research into marsupial gamete biology.

Funding for this research was provided by the New Zealand Foundation for Research, Science and Technology under Contract Number C09301 and the Ministry of Agriculture and Fisheries, Policy Division. The purchase of the stereomicroscope used in this study was assisted by a grant from the New Zealand Lottery Grants Board. The authors thank P. Cowan and T. Fletcher for helpful comments on the manuscript, L. Markham for able technical assistance and L. Milne and the staff of the Landcare Research Animal House.

\section{References}

Cowan PE (1990) Brushtail possum. In The Handbook of New Zeiland Mammals pp 68-98 Ed. CM King. Oxford University Press, Auckland

Harding HR (1969) Studies on the Periovulatory Changes in the Ovary. Uterus, and Vagina of the Marsupial Trichosurus vulpecula (Kerr), and the Effect of Pregnant Mare Serum (PMS) and Human Chorionic Gonadotrophin (hCG) in Inducing Ovulation Honours Thesis, University of New South Wales, Sydney

Hickling GJ (1994) Behavioural resistance by vertebrate pests to 1080 toxin: implications for sustainable pest management in New Zealand Proceedings of the Science Workshop on $1080 \mathbf{2 8}$ pp 151-158 Royal Society of New Zealand Miscellaneous Series

Hinds LA, Fletcher TP and Rodger JC (1996) Hormones of oestrus and ovulation and their manipulation in marsupials Reproduction Fertility and Development 8 $661-672$

Jolly SE (1993) Biological control of possums New Zealand Journal of Zoology 20 335-339

Kaneko H, Kishi H, Watanabe G, Taya K, Sasamoto S and Hasegawa Y (1995) Changes in plasma concentrations of immunoreactive inhibin, estradiol and FSH associated with follicular waves during the estrous cycle of the cow Journal of Reproduction and Development 41 311-320

Livingstone PG (1991) Tuberculosis in New Zealand - current status and control policies Surveillance 19 14-18

Molinia FC, Gibson RJ, Brown AM, Glazier AM and Rodger JC (1998) Successful fertilization after superovulation and laparoscopic intrauterine insemination of the brushtail possum, Trichosurus vuipecula, and tammar wallaby, Macropus eugenii. Journal of Reproduction and Fertility 113 9-17

Molinia FC, Gibson RJ, Smedley MA and Rodger JC Further observations of the ovarian response of the tammar wallaby, Macropus eugenii, to exogenous gonadotrophins: an improved method for the superovulation using FSH/LH. In Reproductive Research in Wildlife Species. Animal Reproduction Science (in press) 
Rodger JC (1994) Prefertilization gamete maturation events in marsupials Reproduction Fertility and Development 6 473-483

Rodger JC (1997) Likely targets for immunocontraception in marsupials Reproduction Fertility and Development $9131-136$

Rodger JC and Mate KE (1988) A PMSG/GnRH method for the superovulation of the monovulatory brush-tailed possum (Trichosurus vulpecula) Journal of Reproduction and Fertility 83 885-891

Spears N, Boland NI, Murray AA and Gosden RG (1994) Mouse oocytes derived from in vitro grown primary ovarian follicles are fertile Human Reproduction 9 527-532
Stewart F and Tyndale-Biscoe CH (1982) Prolactin and luteinizing hormone receptors in the marsupial corpora lutea: relationship to control of luteal function Journal of Endocrinology 92 63-72

Taggart DA, O'Brien HP and Moore HD (1993) Ultrastructural characteristics of in vivo and in vitro fertilization in the grey short-tailed opossum, Monodelphis domestica. Anatomical Record 237 21-37

Tyndale-Biscoe CH and Renfree MB (1987) Reproductive Physiology of Marsupials Monographs on Marsupial Biology 476, Cambridge University Press

Wilkinson L (1989) SYSTAT: The System for Statistics SYSTAT Inc., Evanston, 